\title{
Research into the effectiveness of grounded screens of electroconductive silicate compositions for electrocorrosion protection
}

\author{
Dmytro Plugin ${ }^{1 *}$, Vladimir Kasyanov ${ }^{1}$, Vitalii Konev ${ }^{1}$, Sergii Nesterenko ${ }^{2}$, \\ and Aleksander Afanasiev ${ }^{1}$ \\ ${ }^{1}$ Ukrainian State University of Railway Transport, Building Materials and Structures Department, \\ Feuerbach sq. 7, 61050 Kharkiv, Ukraine \\ ${ }^{2}$ O.M. Beketov National University of Urban Economy in Kharkiv, Land Administration and GIS \\ Department, Kulikovska descent 12, 61002 Kharkiv, Ukraine
}

\begin{abstract}
The effectiveness of coatings based on Portland cement and sodium silicate with graphite filler as an electrocorrosion protection of grounded screens is investigated. An original technique is developed, consisting in comparing the values of the current $I$ through the reinforcement and concrete of the structure model without protection and with protection by grounded screens-coatings. As a result of experimental studies it is found that, in comparison with the model without protection, the $I$ value of the coated model of the Portland cement-based composition is less: by $49-66 \%$, and for the model coated by sodium silicate-based composition - by $34-60 \%$.
\end{abstract}

\section{Introduction}

According to [1, 2], structures close to railways and other sources electrified by direct current are subjected to electrocorrosion. Mainly metal structures and reinforcement of reinforced concrete are corroded. It was noted in [3] that concrete is also corroded near the reinforcement. It was established in [4-6] that the electrocorrosion of concrete proceeds not only near the reinforcement, but even in unreinforced structures and masonry mortar, and consists in the intensive electromigration leaching of the cement stone under the action of a pulsating unidirectional electric potential. This potential is created when trains run along a rail section electrified by a direct current.

In $[4,7]$ it was proposed to apply the diode grounding of metal-injection jacket for electrocorrosion protection of culvert structures. Such jacketing is used to repair damaged pipe structures (Fig. $1 \mathrm{a}, \mathrm{b}$ ). The metal sheathing of the jacket protects concrete and mortar from carbonization and leaching, cement stone of concrete and inside covering - from electrochemical corrosion. However, under the influence of leakage currents, the metal sheathing of the jacket is subjected to electrocorrosion in the anode zones (Fig. $1 \mathrm{c}$ ). Its diode grounding makes it possible to protect both the sheathing itself from electrocorrosion by transferring the anode zones to the ground, and the concrete and the solution of the pipe

* Corresponding author: plugin.da@gmail.com 
structures from the current flow (Fig.1 d). However, the metal-injection jacket is an expensive construction which is useful when it is necessary to restore the bearing capacity of a structure with significant damage. Replacement of metal-injection jacketing by coating, a screen made of an electrically conductive composition based on mineral binders with its grounding, will make it possible to reduce the cost of repair and protection of the structure. However, the effectiveness of such electrocorrosion protection has not previously been investigated. Such studies were carried out by the authors under the guidance of Prof. Andrii Plugin with the participation of Dr. Oleksii Pluhin.

The aim of the research is to determine the magnitude of the reduction in current strength through the concrete structure model as a result of its protection by grounded coating with compositions based on mineral binders.

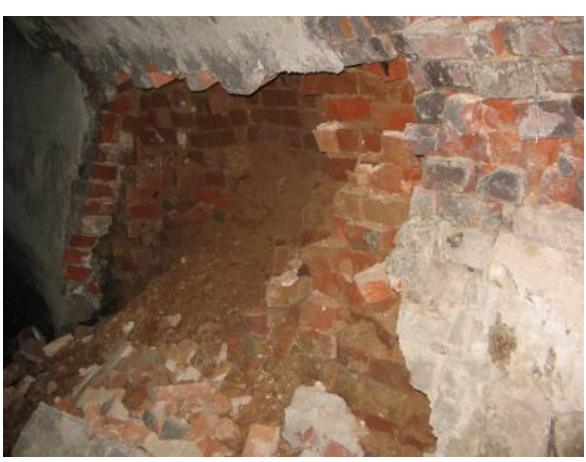

(a)

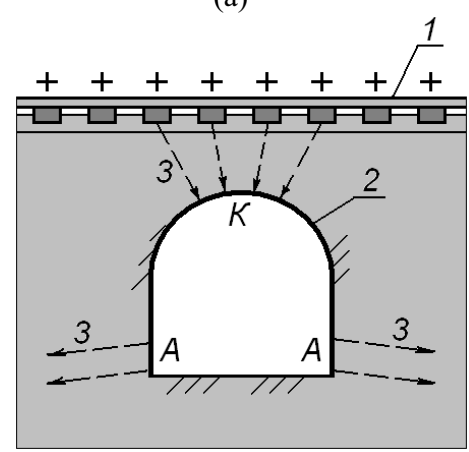

(c)

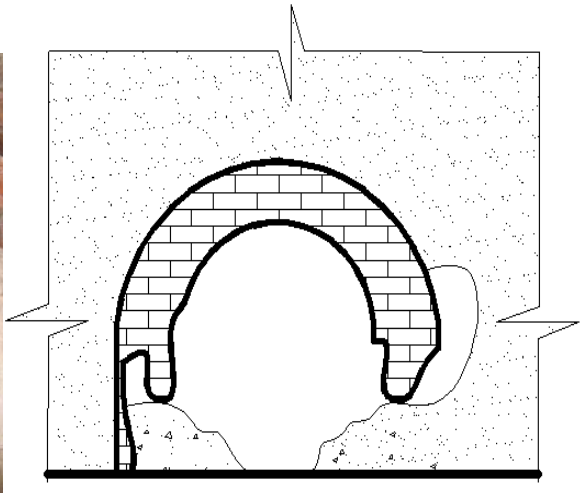

(b)

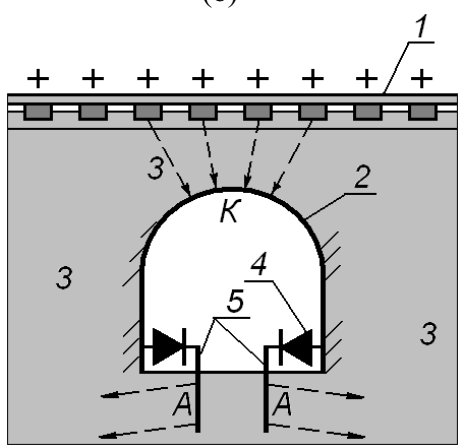

(d)

Fig. 1. Repair and corrosion protection of the culvert pipe in the railway embankment: $(a, b)$ damage in the form of piles; (c, d) leakage current flow from the rails through the unprotected (c) and diodeprotected grounding (d) metal-injection jacket: 1 - rail track; 2 - metal-injection jacket; 3 - leakage currents; 4 - valve (diode) of the protective device; 5 - grounding rod; $\mathrm{K}$ - cathodic area; $\mathrm{A}$ - anodic area (corrosive)

\section{Material and methods}

The effectiveness of grounded coatings, screens made from Portland cement-based compositions as well as sodium silicate hardened with sodium silicofluoride with graphite powder filler, is investigated. The composition formulas are developed at Ukrainian State University of Railway Transport [8].

An original technique for experimental research of the effectiveness of grounded screens made of electrically conductive compositions for electrocorrosion protection of 
structures is developed. The technique compares the electrical current $I$ magnitude flowing through the reinforcement and concrete of the model of a structure without a protective screen $\left(I_{0}\right)$ and the model of a structure with a protective screen $\left(I_{1}\right)$. The reduction in current intensity through concrete and reinforcement of the model with protection $I_{1}$ in comparison with that without protection $I_{0}$ was taken as the efficiency index of the screen:

$$
\Delta I=I_{1} / \mathrm{I}_{0} \times 100 \% .
$$

The models of the structure are developed on the basis of analysis of leakage currents from the rail track through sections of passenger platforms on sections with a positive potential on rails (Fig. 2) without protection (Fig. $2 \mathrm{a}, \mathrm{b}$ ) and with grounded screens (Fig. 2 c, d). As can be seen, in rainy weather, the leakage currents flow through concrete, reinforcement and grounding for the platform without protection, and through the screen and grounding bypassing concrete and reinforcement for the platform with the screen.

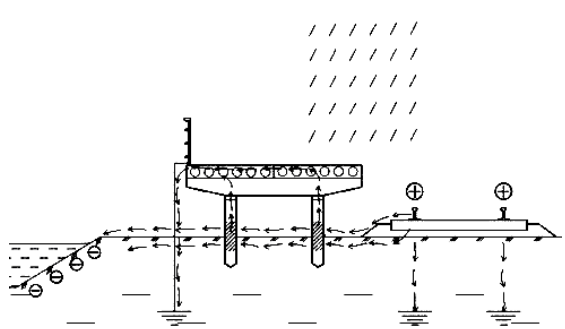

(a)

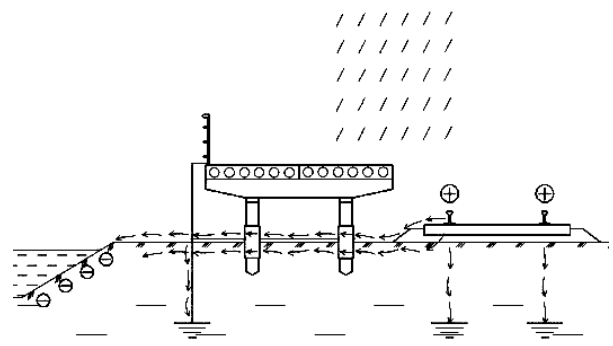

(c)

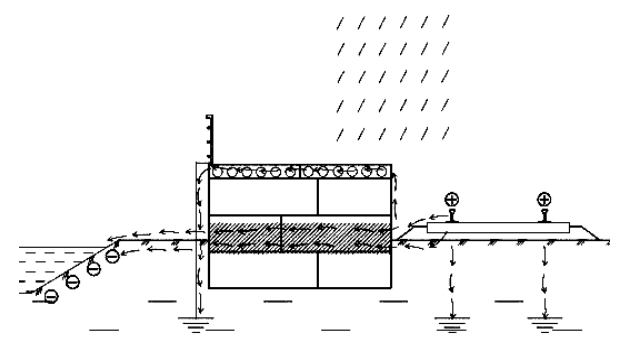

(b)

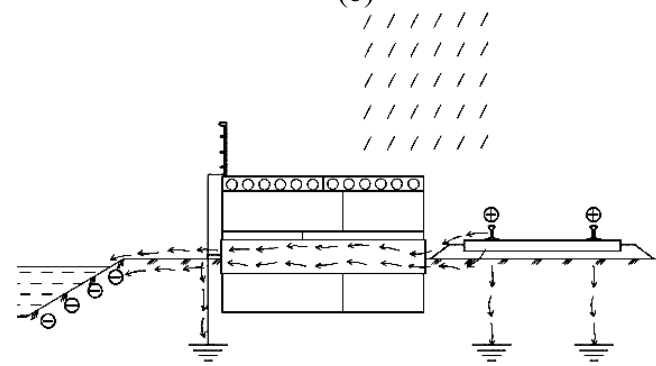

(d)

Fig. 2. The leakage current flows from the rail track in areas with a positive potential on rails through the construction of high passenger platforms: $(a, c)$ on reinforced concrete racks and crossbars; $(b, d)$ on concrete block supports; $(\mathrm{a}, \mathrm{b})$ without protection; (c, d) with grounded screen coatings.

The studies are carried out using a special experimental setup (Fig. 3). The setup consists of a model of the structure - the prism of heavy concrete of a compressive strength of $20 \mathrm{MPa} l$ with an upward built-in rod of reinforced steel 2 . The concrete of the model corresponds to the concrete of the structure between its faces (Fig. 2a) or the concrete of a protective layer between grounded reinforcement and face of the structure (Fig. 2b). This model prism is installed in a model of moistened soil, very fine sand 4, put into a metal container 3. The current flowing into the structure from direct current sources, e.g., an electrified rail track, is created (simulated) by application of a potential difference of $40 \mathrm{~V}$ between container 3 and reinforcement rod 2 in prism 1 , and the current strength is measured with the ammeters included in the chain (digital multimeters Sanwa PC510) 8 and 9 . The measurements begin at a dry state of the soil, and then it is water-saturated; they continue during 240 hours with a periodicity of 1 hour first, then 6, 12 and 24 hours. The results are presented as the graphs of dependence of current $I$ on time $t$ and the value of 
current reduction through the concrete and reinforcement of the model with protection in comparison with the model without protection $\Delta I$.

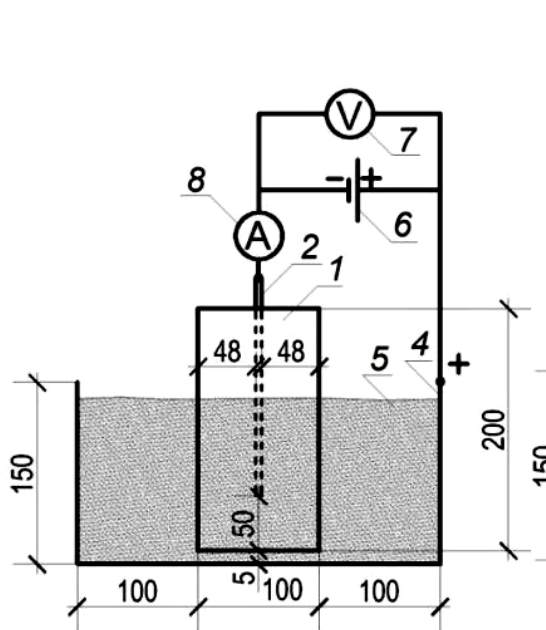

(a)

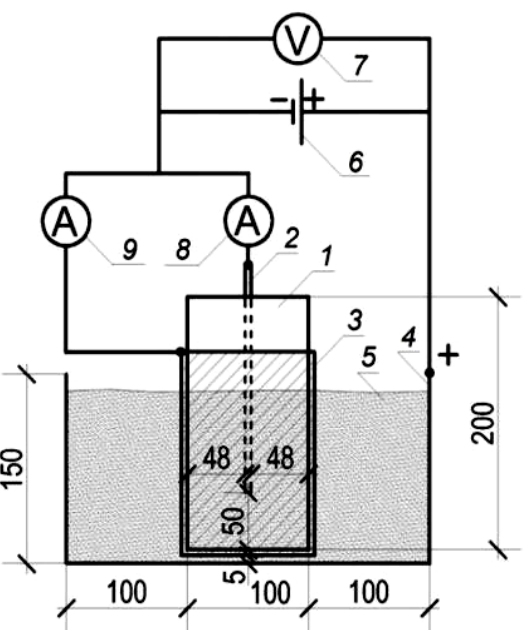

(b)

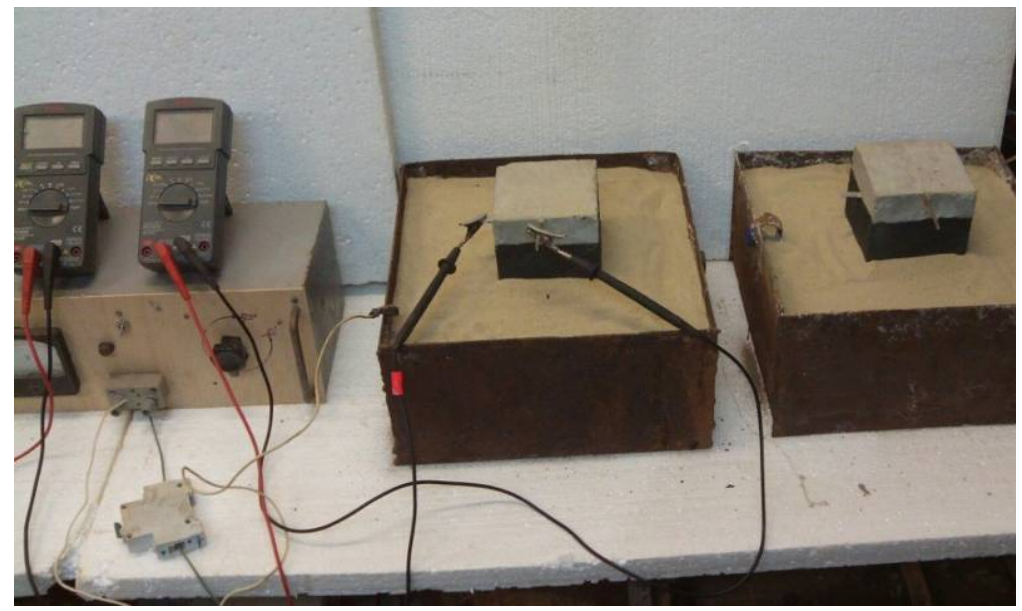

(c)

Fig. 3. Setups for the experimental study of effectiveness of screens of electroconductive compositions for electrocorrosion protection of structures: $(\mathrm{a}, \mathrm{b})$ a schematic diagram of the setup with a control sample (model of a structure) without a screen (a) and with a test sample (structure model) with a screen of electroconductive composition (b); (c) view of experimental setups; 1 concrete of the model; 2 - reinforced rod of the model; 3 - protective screen (coating); 4 - metal container; 5 - moistened sand; 6 - current source; 7 -voltmeter; 8 - milliammeter for measuring the current intensity through reinforcement and concrete $I_{r c} ; 9$ - milliammeter for measuring the current intensity through the screen and the soil $I_{s g}$ 


\section{Research results and their discussion}

The results of the research into effectiveness of grounded screens made of electroconductive compositions based on mineral binders for electrocorrosion protection of structures are given in Fig. 4.

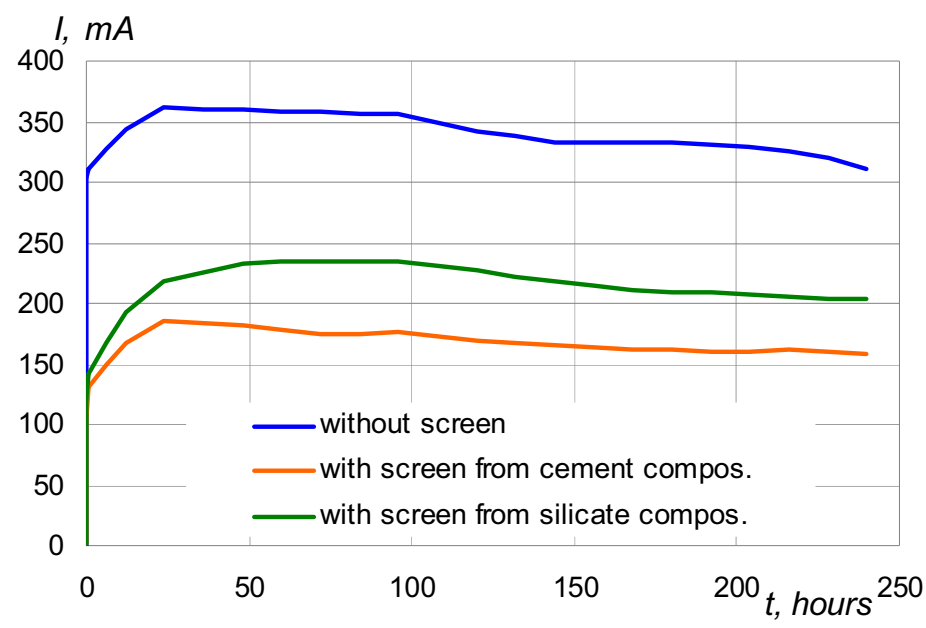

(a)

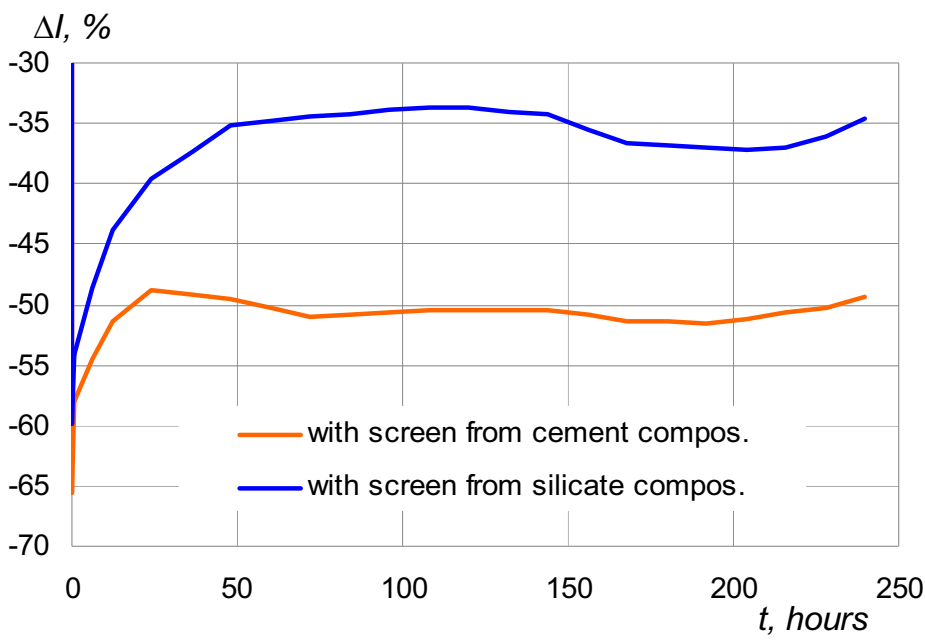

(b)

Fig. 4 Results of the research into effectiveness of screens made of electroconductive compositions based on Portland cement and sodium silicate: (a) dependence of current $I$ through reinforcement and concrete of the model without a protective screen (control) and with protective screens on the time since the soil is water saturated $t$ : (b) dependence of change in current strength through reinforcement and concrete of the model with protective screens in comparison with the model without protection $\Delta I$ on time $t$.

As can be seen from Fig. 4, in the case of a dry state of the soil (at the beginning of the experiment at $\mathrm{t}=0$ ), the current intensity through reinforcement and concrete $I$ is minimal for both the model of the structure without protection and models with protective screens. When the soil is water saturated the current strength increases by three orders of magnitude, 
and in comparison with the model without protection, the current strength $I$ in the model with a screen made of Portland cement composition is less by $49-66 \%$, and in the model with a screen made of sodium silicates and calcium composition it is less by $34-60 \%$. This confirms the effectiveness of grounded screens for electrocorrosion protection of structures, e.g., passenger platforms, from leakage currents.

However, during the study, the effect of the contact area of the screen grounding on the measured current strength is noted. The study of this influence is underway.

\section{Conclusions}

A technique for the experimental study into the effectiveness of screens made of electroconductive silicate compositions for electrocorrosion protection of structures is developed; it consists in comparing the magnitude of the electric current $I$ flowing through reinforcement and concrete of the model of a structure without a protective screen, and the model of a structure with a protective screen, and defining the reduction in the current strength through concrete and reinforcement of the model with protection in comparison with the model without protection $\Delta I$.

The effectiveness of grounded screens for electrocorrosion protection of structures, e.g., passenger platforms from leakage currents is experimentally confirmed. Thus, it is established that in the case of dry soil conditions, the current strength through reinforcement and concrete $I_{r c}$ is minimal in both the model of a structure without protection and models with protective screens. When the soil is water saturated, the current strength increases by three orders of magnitude, and in comparison with the model without protection, the value $I$ in the model with the screen of Portland cement composition is less by $49-66 \%$, and in the model with the screen of sodium silicates and calcium composition it is less by $34-60 \%$.

\section{References}

1. I.A. Kornfeld, V.A. Pritula, Zashchita zhelezobetonnykh konstruktsiy ot elektrokorrozii, vyzyvayemoy bluzhdayushchimi tokami (Stroyizdat, Moscow, 1964)

2. A.V. Kotelnikov, Bluzhdayushchiye toki elektrifitsirovannogo transporta (Transport, Moscow, 1986)

3. A.A. Staroselskiy, Elektrokorroziya zhelezobetona (Budivelnik, Kyiv, 1978)

4. O.A. Pluhin, O.S. Borzyak, V.B. Martinova, O.K. Khalyushev, Yelektrichni vplivi na beton, ed. A.A. Plugin and M.M. Zaychenko (Fort, Kharkiv, 2013)

5. A.N. Plugin, A.A. Plugin, O.A. Pluhin, O.A. Dudin, O.S. Borzyak, 17 Internationale Baustofftagung, Weimar, 2, 1151-1156 (2009)

6. O.A. Pluhin, Collected scientific works of Ukrainian State University of Railway Transport, 115, 56-67 (2010)

7. O.A. Pluhin, O.S. Borzyak, O.A. Dudin, J.A. Konev, A.A. Plugin, Collected scientific works of Ukrainian State University of Railway Transport, 127, 204-212 (2011)

8. A.A. Plugin, T.O. Kostiuk, O.A. Pluhin, D.O. Bondarenko, N.M. Partala, Yu.A. Sukhanova. Kompozytsiia pronyknoi dii dlia hidroizoliatsii ta zakhystu vid elektrokorozii: UA113600[P]. (2017-02-10) 